\title{
Long-term lentiviral-mediated expression of ciliary neurotrophic factor in the striatum of Huntington's disease transgenic mice
}

\author{
Diana Zala, ${ }^{\mathrm{a}}$ Jean-Charles Bensadoun, ${ }^{\mathrm{a}}$ Luis Pereira de Almeida, ${ }^{\mathrm{b}}$ Blair R. Leavitt, ${ }^{\mathrm{c}}$ \\ Claire-Anne Gutekunst, ${ }^{\mathrm{d}}$ Patrick Aebischer, ${ }^{\mathrm{a}}$ Michael R. Hayden, ${ }^{\mathrm{c}}$ and Nicole Déglon ${ }^{\mathrm{a}, *}$ \\ ${ }^{a}$ Institute of Neuroscience, Swiss Federal Institute of Technology Lausanne, Lausanne, Switzerland \\ ${ }^{\mathrm{b}}$ Faculty of Pharmacy and Center for Neuroscience, University of Coimbra, Coimbra, Portugal \\ ${ }^{\mathrm{c}}$ Department of Medical Genetics, Centre for Molecular Medicine and Therapeutics, Vancouver, Canada \\ ${ }^{\mathrm{d}}$ Department of Neurology, Emory University School of Medicine, Atlanta, GA, USA
}

Received 3 June 2003; revised 26 August 2003; accepted 4 September 2003

\begin{abstract}
Ciliary neurotrophic factor (CNTF) has been shown to prevent behavioral deficits and striatal degeneration in neurotoxic models of Huntington's disease (HD), but its effect in a genetic model has not been evaluated. Lentiviral vectors expressing the human CNTF or LacZ reporter gene were therefore injected in the striatum of wild-type (WT) and transgenic mice expressing full-length huntingtin with 72 CAG repeats (YAC72). Behavioral analysis showed increased locomotor activity in 5- to 6-month-old YAC72-LacZ mice compared to WT-LacZ animals. Interestingly, CNTF expression reduced the activity levels of YAC72 mice compared to control animals. In both WT and YAC72 mice, CNTF expression was demonstrated in striatal punches, up to a year after lentiviral injection. Stereological analysis revealed that the number of LacZ and DARPP-32-positive neurons were decreased in YAC72-LacZ mice compared to WT-LacZ animals. Assessment of the benefit of CNTF expression in the YAC72 mice was, however, complicated by a down-regulation of DARPP-32 and to a lesser extent of NeuN in all mice treated with CNTF. The expression of the neuronal marker NADPH-d was unaffected by CNTF, but expression of the astrocytic marker glial fibrillary acidic protein (GFAP) was increased. Finally, a reduction of the number of striatal dark cells was observed in YAC mice treated with CNTF compared to LacZ. These data indicate that sustained striatal expression of CNTF can be achieved with lentiviruses. Further studies are, however, needed to investigate the intracellular signaling pathways mediating the long-term effects of CNTF expression on dopamine signaling, glial cell activation and how these changes may affect HD pathology.
\end{abstract}

(C) 2003 Elsevier Inc. All rights reserved.

Keywords: Huntington's disease; Lentiviral vector; Gene therapy; CNTF; Ciliary neurotrophic factor; HD transgenic mice

\section{Introduction}

Huntington's disease (HD) is a fatal dominant disorder characterized by a selective neuronal loss in the striatum and to a lesser extent in the cortex (Vonsattel and Difiglia, 1998). The disorder is caused by an expansion of a CAG repeat tract in the HD gene (The Huntington's Disease Collaborative Research Group, 1993) which can be used to genetically identify presymptomatic individuals who are at-risk for developing the disease (Andrew et al., 1993). Initiation of therapeutic interventions before the onset of clinical symptoms and neuronal degeneration can therefore be

* Corresponding author. Institute of Neuroscience, Swiss Federal Institute of Technology Lausanne, EPFLSG AAB-135, 1015 Lausanne, Switzerland. Fax: +41-21-693-95-20.

E-mail address: nicole.deglon@epfl.ch (N. Déglon). envisaged. Over the last few years, neuroprotective strategies based on the use of neurotrophic factors have been developed, and significant rescue of striatal neurons associated with behavioral improvement was observed in druginduced models of HD (Anderson et al., 1996; Araujo and Hilt, 1998; Bemelmans et al., 1999; Emerich et al., 1996; Frim et al., 1993; Mittoux et al., 2000; Perez-Navarro et al., 1999, 2000; Volpe et al., 1998).

Ciliary neurotrophic factor (CNTF) (Ip and Yancopoulos, 1996), a member of the cytokine family, has been shown to prevent behavioral deficits and striatal degeneration in quinolinic acid-lesioned rats and primates (Anderson et al., 1996; de Almeida et al., 2001; Emerich et al., 1996, 1997a,b). Recently, we have further investigated whether CNTF could reduce neuronal dysfunction and neurodegeneration in monkeys chronically treated with 3-nitropropionic acid (3-NP) (Mittoux et al., 2000). This study demonstrated 
that the intracerebral and continuous delivery of CNTF at the time of appearance of striatal dysfunction and motor/ cognitive symptoms, not only prevents neuronal degeneration, but also alleviates functional deficits. Moreover, Saudou et al. (1998) have demonstrated that CNTF rescues primary rat striatal cultures from cell death caused by the expression of a mutant htt fragment. This in vitro study suggests that CNTF might alter the degeneration of GABAergic neurons in a genetic model of the disease.

In the present study, we have assessed the effect of longterm CNTF delivery in wild-type mice and HD YAC transgenic mice expressing full-length htt with $72 \mathrm{CAG}$ repeats (Hodgson et al., 1999). These animals show electrophysiological abnormalities at 6 months, a mild hyperkinetic movement disorder with a significantly increased activity between 5 and 9 months. By 12 months of age, these mice display an increase in the number of striatal dark cells as measured by toluidine blue staining (Hodgson et al., 1999). Lentiviral vectors were used to achieve local and long-term delivery of CNTF in the brain while avoiding side effects associated with systemic administration (Abicht and Lochmuller, 1999). Lentiviruses expressing LacZ or human CNTF were bilaterally injected into the corpus striata of 4-month-old YAC72 mice and wild-type littermates. Behavioral analyses were performed during the entire experiment to monitor the progression of the disease. Finally, at 13 months of age, the animals were sacrificed and their brains processed to assess the effects of long-term CNTF expression.

\section{Materials and methods}

\section{Lentiviral vector production}

The cDNA coding for a nuclear-localized $\beta$-galactosidase (LacZ) and the human CNTF (Aebischer et al., 1996) were cloned in the SIN-W-PGK transfer vector (de Almeida et al., 2001; Déglon et al., 2000). The packaging construct and the vesicular stomatitis virus G protein (VSV-G) envelope used in this study were the pCMV $\Delta R-8.92$, pRSV-Rev and pMD.G plasmids (Dull et al., 1998; Hottinger et al., 2000; Naldini et al., 1996). The viral particles were produced by transient transfection of $293 \mathrm{~T}$ cells as previously described (Hottinger et al., 2000). LacZ- and CNTF-expressing viruses were resuspended in phosphate-buffered saline (PBS) with $1 \%$ bovine serum albumin and matched for particle content of 100,000 ng p24 antigen/ml as measurement by ELISA (Perkin Elmer Life Sciences, MA, USA).

\section{In vivo experiments}

YAC72 mice and littermate wild type (mouse line FVBTgN (353G6-72) 2511, YAC72) and wild-type FVB/N (IffaCredo, France) mice (Hodgson et al., 1999) were used in these studies. The animals were housed in a controlled temperature room that was maintained on a $12 \mathrm{~h}$ light/dark cycle. Food and water were available ad libitum. The animals injected with lentiviral vectors were maintained in ventilated cabinets in biosafety level 2 laboratories. The experiments were carried out in accordance with the European Community Council directive (86/609/EEC) for care and use of laboratory animals.

\section{Injection of the lentiviruses}

The concentrated viral stocks were thawed and re-suspended by repeated pipetting. CNTF or LacZ-expressing lentiviral vectors were stereotaxically injected in the left $(1$ $\mu \mathrm{l})$ and right $(1 \mu \mathrm{l})$ striatum of 4-month-old pentobarbital anesthetized (75 mg/kg, i.p.) FVB/N and YAC72 mice using a Hamilton syringe with a 33-gauge blunt tip needle (Hamilton, Reno, NV, USA). The stereotaxic coordinates for the injection were: $0.4 \mathrm{~mm}$ rostral to bregma; $1.8 \mathrm{~mm}$ lateral to midline (LM); $3.5 \mathrm{~mm}$ ventral from the dural surface. The suspension was injected at $0.2 \mu \mathrm{l} / \mathrm{min}$ by means of an automatic injector (Stoelting Co., IL, USA) and the needle was left in place for $5 \mathrm{~min}$. The skin was closed using a 6-0 Vicryl suture (Ethicon, Johnson and Johnson, Brussels).

\section{Behavioral analysis}

Mice were placed in a monitoring box $(10 \times 10 \times 30 \mathrm{~cm})$ (Digiscan Animal Activity Monitor, AccuScan Instruments, $\mathrm{OH}, \mathrm{USA}$ ) and their activity recorded for $2 \mathrm{~h}$. Infrared beam breaks were converted into total distance traveled. The activity was tested every other week at a fixed time corresponding to the dark phase period for the animals (inverted light cycle). The test was performed during the entire experimental period.

\section{CNTF measurements}

The animals were sacrificed, perfused in ice-cold PBS containing $0.02 \%$ ascorbic acid (Sigma, MO, USA) and $5000 \mathrm{U}$ of heparin (Liquemin, Roche Pharma, Reinach, Switzerland). The in vivo synthesis of CNTF was determined from 2-mm-long striatal punches taken around the injection sites and from corresponding non-injected hemispheres. The samples were rapidly frozen on dry ice and kept at $-80^{\circ} \mathrm{C}$ until processing. The samples were sonicated in $500 \mu \mathrm{l}$ PBS, containing a cocktail of protease inhibitors (pronase, thermolysin, chymotrypsin, trypsin, papain; Roche Pharma, Reinach, Switzerland). Quantitative analysis of the production of CNTF was performed by an ELISA assay according to the supplier's manual (R\&D system, Abington, UK).

\section{Histological processing}

The mice were sacrificed by a sodium pentobarbital overdose and then transcardially perfused with a $4 \%$ para- 
formaldehyde containing saline solution. The brains were removed, weighed and one hemisphere was post-fixed in $4 \%$ paraformaldehyde for approximately $24 \mathrm{~h}$ and cryoprotected in $25 \%$ sucrose $/ 0.1 \mathrm{M}$ PBS for $48 \mathrm{~h}$. These samples were frozen in dry ice and coronal sections were cut on a sliding microtome cryostat (Cryocut 1800, Leica Microsystems, Nußloch, Germany) at a temperature of $-20^{\circ} \mathrm{C}$ and a thickness of $20 \mu \mathrm{m}$. Slices throughout the entire striatum were collected and stored in 48-well trays (Costar, Cambridge, MA, USA) as free-floating sections in PBS containing $0.12 \mu \mathrm{M}$ sodium azide. The trays were stored at $4{ }^{\circ} \mathrm{C}$ until immunohistochemical processing.

The second brain hemisphere was post-fixed in $0.15 \%$ glutaraldehyde in 0.1 M PBS ( $\mathrm{pH}$ 7.2). Fifty-micrometer sections were cut with a Leica Ultracut ultramicrotome and cresyl violet stained to assess the appearance of dark cells. Sections were put for $2 \mathrm{~min}$ in sodium acetate solution containing $0.5 \%$ cresyl violet (Sigma) and than rinsed in the acetate solution. The sections were dehydrated in ethanol, passed in toluol and coverslipped with Merckoglas.

\section{Histochemical analysis}

Enzymatic staining for nicotinamide adenine dinucleotide phosphate diaphorase (NADPH-d) was performed as previously described (Ellison et al., 1987). For immunohistochemical stainings, endogenous peroxidase activity was quenched with $0.1 \%$ diphenylhydrazine/PBS $\left(37^{\circ} \mathrm{C}\right.$ for $\left.30 \mathrm{~min}\right)$ and washed 3 times in PBS. Free-floating sections were incubated overnight in 5\% normal goat serum (NGS, Dako Diagnostics, Untermüli, Switzerland) $/ 0.1 \mathrm{M}$ PBS at $4{ }^{\circ} \mathrm{C}$, followed by an overnight reaction in a $\mathrm{PBS} / 1 \%$ NGS solution, with the respective antibodies: DARPP-32 (1:5000, Chemicon, CA, USA), LacZ (1:500, 5 Prime 3 Prime Inc., USA), glial fibrillary acidic protein (GFAP, 1:300, Clontech, CA, USA)

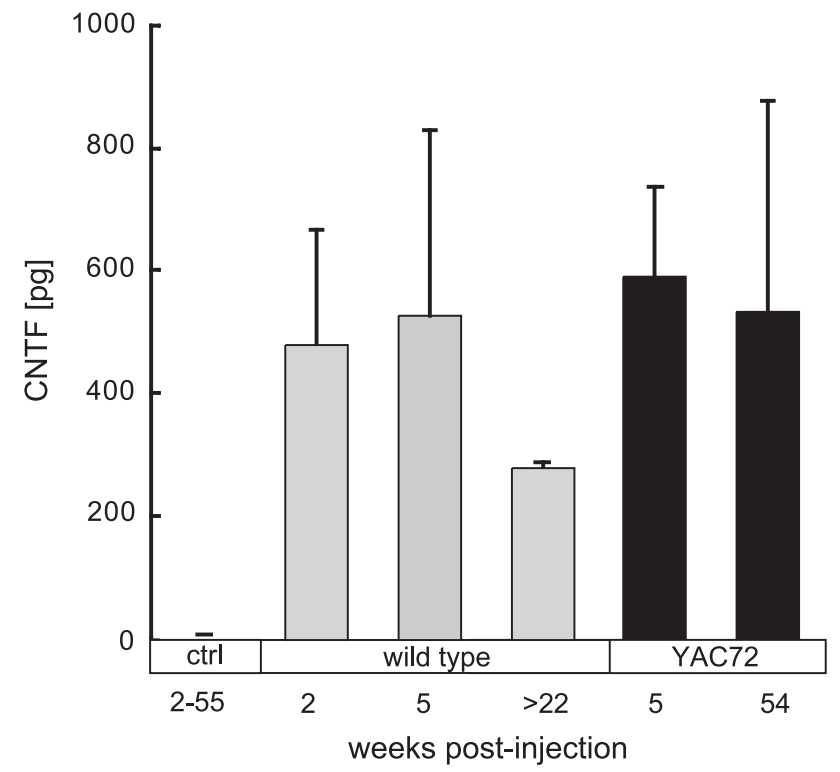

Fig. 2. Sustained lentiviral-mediated expression of CNTF in the striatum of mice. Striatal punches from wild-type and YAC72 transgenic mice were taken 2-54 weeks post-injection of CNTF- or LacZ-expressing lentiviral vectors and processed for ELISA assay. Values below the detection level $(20 \mathrm{pg})$ were measured on non-injected hemispheres or LacZ-infected striata (ctrl). Values are expressed as mean \pm SEM.

and neuronal nuclei (NeuN, 1:400, Chemicon). After three washes, the sections were incubated with the corresponding biotinylated secondary antibodies (1:200, Vector Laboratories, CA, USA) for $2 \mathrm{~h}$ at room temperature. Bound antibodies were visualized with the $\mathrm{ABC}$ system (Vectastain $\mathrm{ABC}$ Kit, Vector Laboratories) and 3,3' -diaminobenzidin as chromogen (DAB Metal Concentrate, Pierce, IL, USA). The sections were dehydrated in ethanol, passed in toluol and coverslipped with Merckoglas. Secondary antibodies coupled to fluorescent chromophores (Jackson ImmunoResearch

pCMV $\Delta$ R-8.92
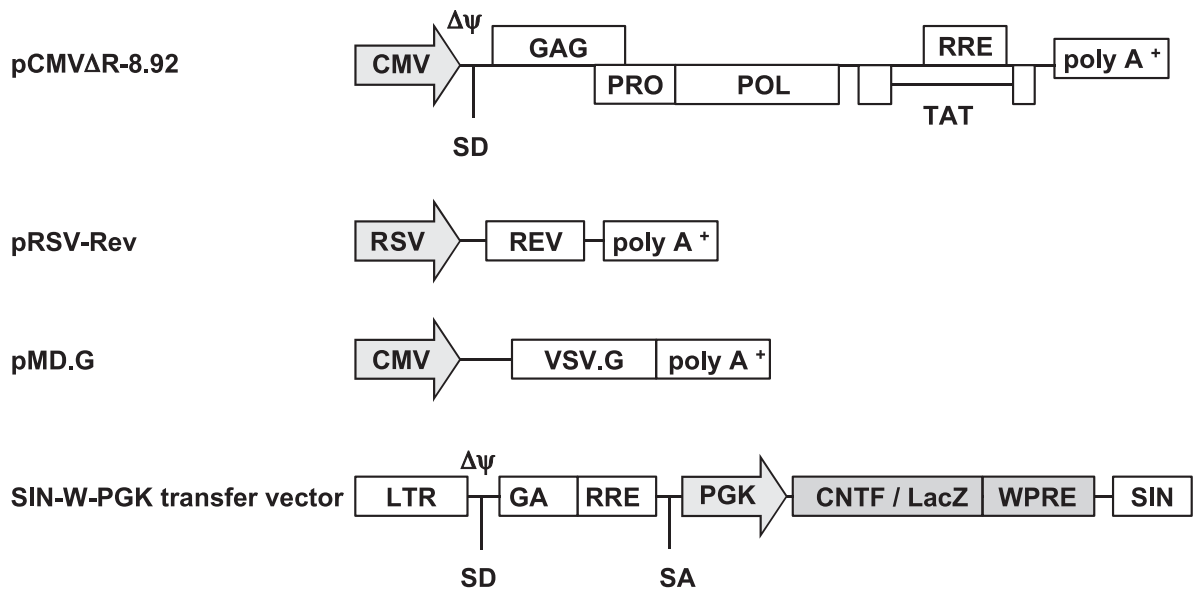

Fig. 1. Schematic representation of the four plasmids used for the production of lentiviral vectors in 293 T cells. pMD.G (VSV-G envelope), pCMV $\Delta R-8.92$ (Packaging construct), pRSV-Rev (Rev protein) and SIN-W-PGK (transfer vector). CMV: cytomegalovirus promoter. GAG: structural precursor protein producing the matrix, capsid and nucleocapsid. LTR: long-terminal repeat. PGK: mouse phosphoglycerate kinase 1 promoter. RSV: Rous sarcoma virus promoter. RRE: Rev-responsive element. SA: splice acceptor. SD: splice donor. SIN: self-inactivating (deletion of the U3 region of the $3^{\prime}$ LTR). POL: sequence coding for the reverse transcriptase and integrase. PolyA $\mathrm{A}^{+}$: polyadenylation signal. PRO: protease. $\psi$ : packaging signal. VSV.G: vesicular stomatitis virus G glycoprotein. WPRE: post-transcriptional regulatory element from the woodchuk hepatitis virus. 


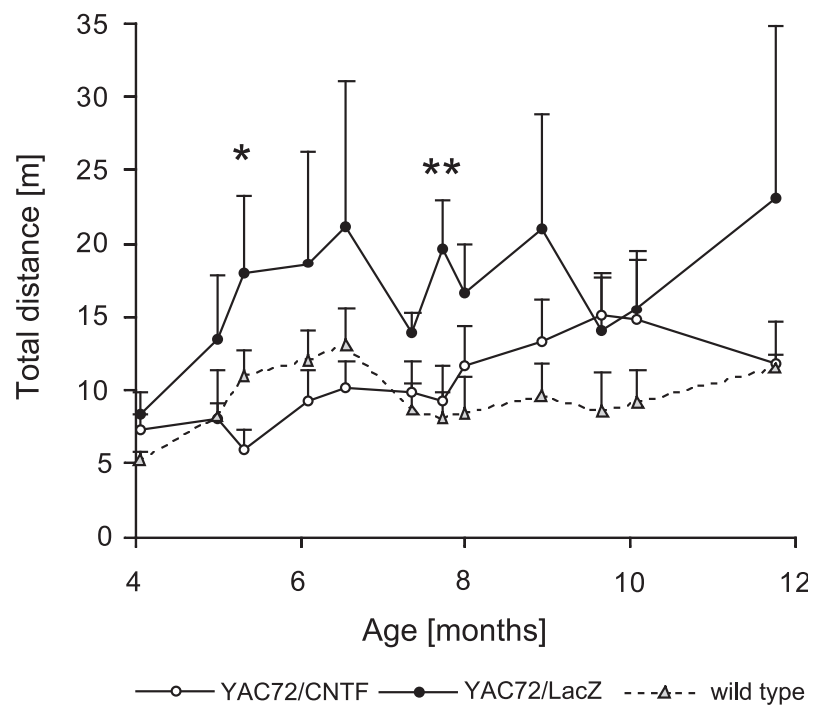

Fig. 3. Decreased hyperactivity in CNTF-treated YAC72 mice. Values represent the mean of total distance in meters traveled in the activity box during $2 \mathrm{~h}$. The general activity of WT/LacZ and WT/CNTF mice were similar and have been plotted together in the graph. LacZ-injected transgenic mice $(n=6)$ displayed an increased activity starting at 5 months of age, whereas YAC/CNTF mice $(n=7)$ displayed a normal activity. Significant differences between the YAC/LacZ and the YAC/CNTF groups were found at 5 and 8 months (* $P=0.04, * * P=0.03)$. Values are expressed as mean \pm SEM.
Laboratories, West Grove, USA) were used for LacZ (FITCgoat anti-rabbit, 1:200). The sections were mounted on glass slides with Fluorsave Reagent (Calbiochem-Novabiochem Corporation, CA, USA).

\section{Quantification of NADPH-d and LacZ-positive cells}

Counts were performed on 9 NADPH-d stained sections per animal $(240 \mu \mathrm{m}$ apart $)$ and $18 \mathrm{LacZ}$-stained sections per animal (120 $\mu \mathrm{m}$ apart). The number of cells was extrapolated with the Abercrombie's equation with the following parameters: section thickness, $20 \mu \mathrm{m}$; nuclear diameter, 5 $\mu \mathrm{m}$; section selection, $1 / 8$ for LacZ and 1/16 for NADPH-d.

\section{Stereological analysis}

The quantification of the DARPP-32 and NeuN cells was performed on 18 sections (120 $\mu \mathrm{m}$ apart) per animal with an Olympus microscope and analyzed with the stereological software C.A.S.T. Grid (The International Stereology Center Olympus Albertslund, Denmark) using the optical dissector method. Briefly, the striatum area (ROI) was defined at low magnification $(1.25 \times)$ and striatum volume was integrated using the method of Cavalieri. Neuronal count was performed at a magnification of $100 \times$ on grid of $500 \mu \mathrm{m} \times 300$

A

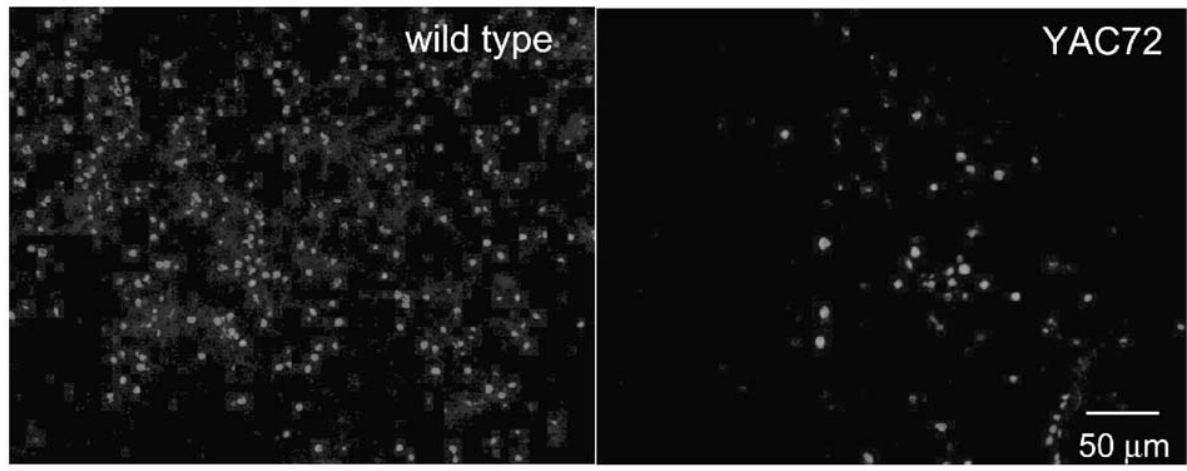

B

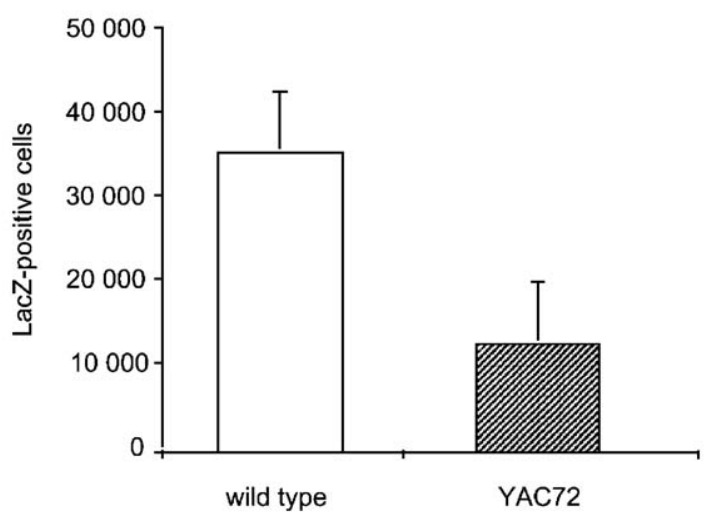

Fig. 4. Loss of LacZ-positive cells in the striatum of YAC72 mice at 9 months post-injection. (A) Photomicrograph of LacZ-infected cells in the striatum of a wild-type and YAC72 mice. (B) Histogram showing the number of LacZ-infected cells in wild-type $(n=2)$ and YAC72 $(n=6)$ mice. Values are expressed as mean \pm SEM. 
$\mu \mathrm{m}$ and the optical dissector was set at $10 \mu \mathrm{m}$. An average of 20 grids was used per section analyzed.

\section{Data analyses}

Data are expressed as mean \pm SEM and evaluated for analysis of variance (ANOVA) followed by a Scheffe's PLSD post hoc test (JMP 3.0, SAS Institute Inc., USA). The significance level was set at $P<0.05$.

\section{Results}

Stable and long-term transgene expression in the striatum

Fig. 1 shows the lentiviral vectors used for the assessment of long-term in vivo expression of CNTF in wild-type and YAC72 mice. Striatal punches, collected up to a year post-lentiviral injection, were processed for ELISA. Average values of approximately $500 \mathrm{pg}$ CNTF/punch were measured, whereas no CNTF was detected in control animals or in animals injected with LacZ lentiviral vectors (Fig. 2). CNTF expression was sustained and no significant differences were observed over time, or between wild-type and YAC72 mice (Fig. 2). These results further demonstrate that lentiviral vectors lead to long-term and sustained transgene expression in the CNS (Déglon and Aebischer, 2002).

Interestingly, the local and continuous delivery of CNTF in the striatum of these mice was not associated with a loss in body weight $(26 \pm 1 \mathrm{~g} \mathrm{WT-LacZ} \mathrm{vs.} 26 \pm 4 \mathrm{~g} \mathrm{WT-CNTF}$ at 13 months), a side effect previously observed with systemic administration of this neurotrophic factor (Penn et al., 1997).

\section{A}
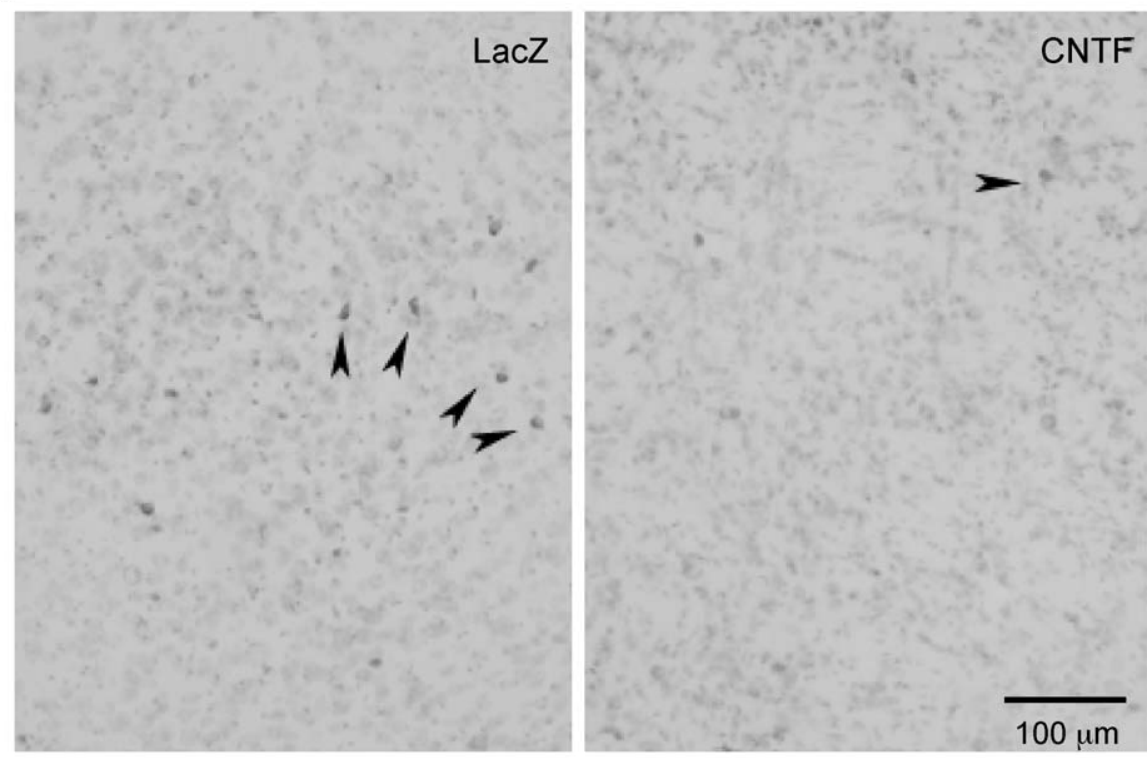

B

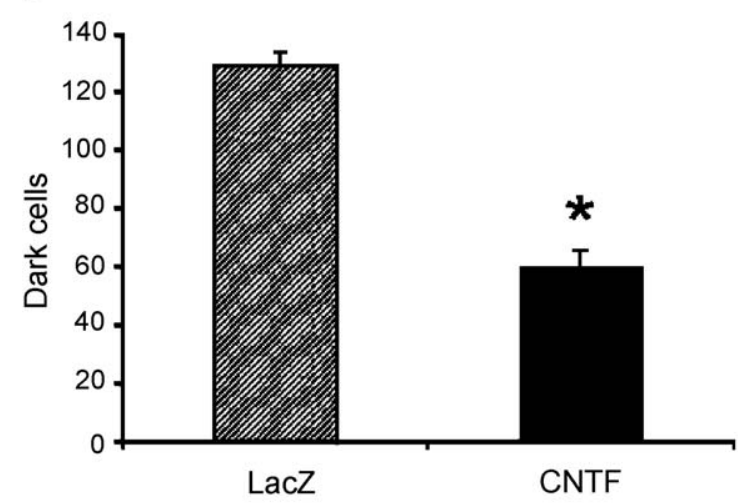

Fig. 5. Significant reduction of cresyl violet-stained dark cells in YAC72-CNTF mice. (A) Photomicrographs of dark cells in the striatum of YAC72 mice injected with a LacZ- or CNTF-expressing lentivirus. Arrows show some hyperchromatic and shrunken cells. (B) Histogram showing the total number of degenerating cells in the striatum of YAC72-CNTF $(n=7)$ and YAC72-LacZ $(n=6)(* P<0.001)$. Values are expressed as mean \pm SEM. 
A

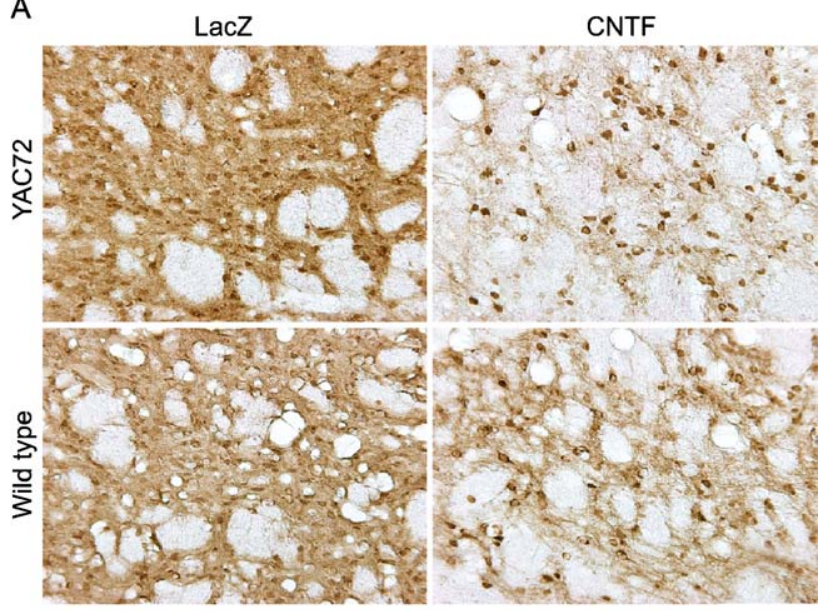

B

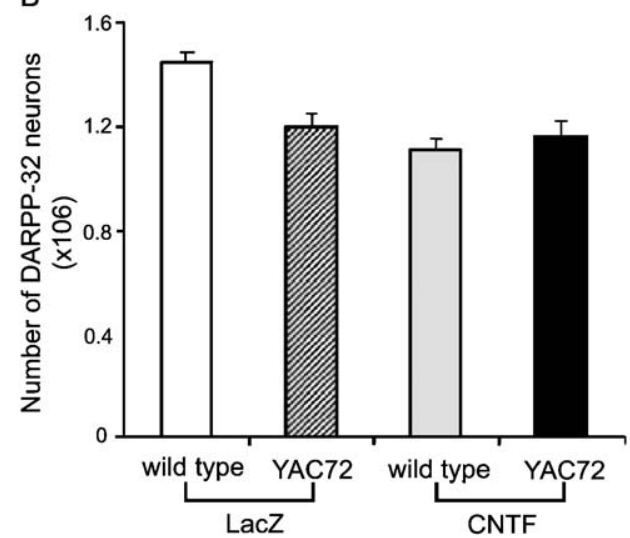

Fig. 6. Stereological counts of DARPP-32-positive neurons. (A) DARPP32-stained striatal sections from WT-LacZ, WT-CNTF, YAC72-LacZ and YAC72-CNTF. (B) Quantification of the total number of DARPP-32positive cells in the striatum of WT-LacZ $(n=3)$, WT-CNTF $(n=3)$, YAC72-LacZ $(n=6)$ and YAC72-CNTF $(n=7)$ mice. Values are expressed as mean $\pm \mathrm{SEM}$.

CNTF delivery decreases the behavioral deficit of YAC72 mice

The appearance of behavioral abnormalities, in particular hyperactivity, was assessed by measuring locomotor activity with the open field test (Fig. 3). A progressive spontaneous hyperactivity, starting at 5 months of age, was observed in the YAC72-LacZ mice (Fig. 3). Although a large inter- and intra-individual variability was observed, the total distance traveled was higher in YAC72-LacZ mice than in wild-type animals. At 7 and 8 months, a significant hyperactivity was recorded in the YAC72-LacZ mice compared to the WT group (Fig. 3). Importantly, CNTF-treated mice displayed lower spontaneous activities compared to YAC72-LacZ mice and statistically significant differences were observed at $5(P=0.04)$ and 8 months $(P=0.03)$ (Fig. 3). Performances in other behavioral tests such as foot-clasping and rotarod did not differ significantly between groups (data not shown).

\section{Brain weight and LacZ expression}

Mouse brains were weighed to assess the global brain weight loss. At 13 months of age, no significant differences were observed between wild-type and YAC72 mice (WT-LacZ $(n=3): 0.610 \pm 0.058 \mathrm{~g}$, WT-CNTF $(n=3)$ : $0.581 \pm 0.038 \mathrm{~g}$, YAC72-LacZ $(n=6): 0.576 \pm 0.006 \mathrm{~g}$, YAC72-CNTF $(n=6): 0.599 \pm 0.013 \mathrm{~g})$.

In wild-type mice, $35,629 \pm 6662$ LacZ-infected cells covering a large area of the striatum were detected 9 months post-injection (Fig. 4A). These results correspond to the typical infected area observed 2 weeks post-infection (data not shown). Interestingly, a smaller number of LacZ-positive cells $(12,709 \pm 464)$ was observed in YAC72-LacZ injected animals probably due to the loss of infected cells (Fig. 4B). Large nuclear structures with intense LacZ staining were observed in the striatum of YAC72-LacZ mice but

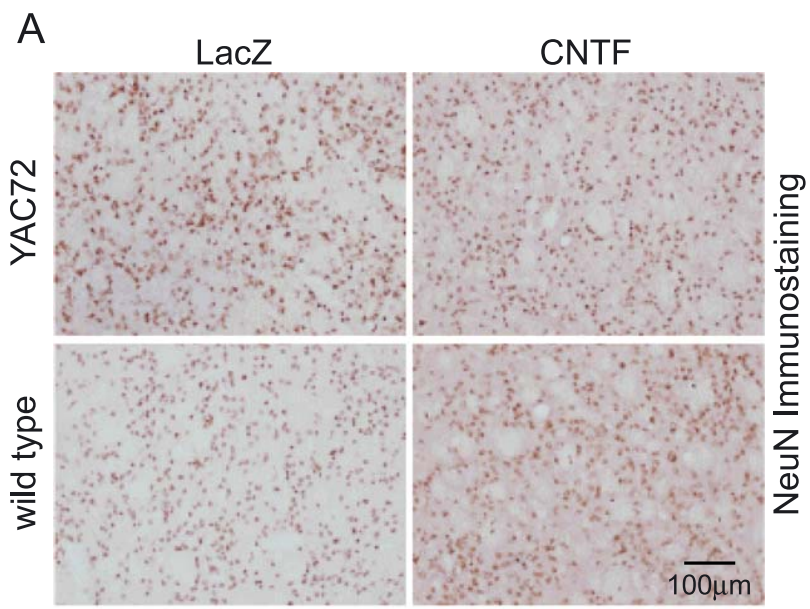

B
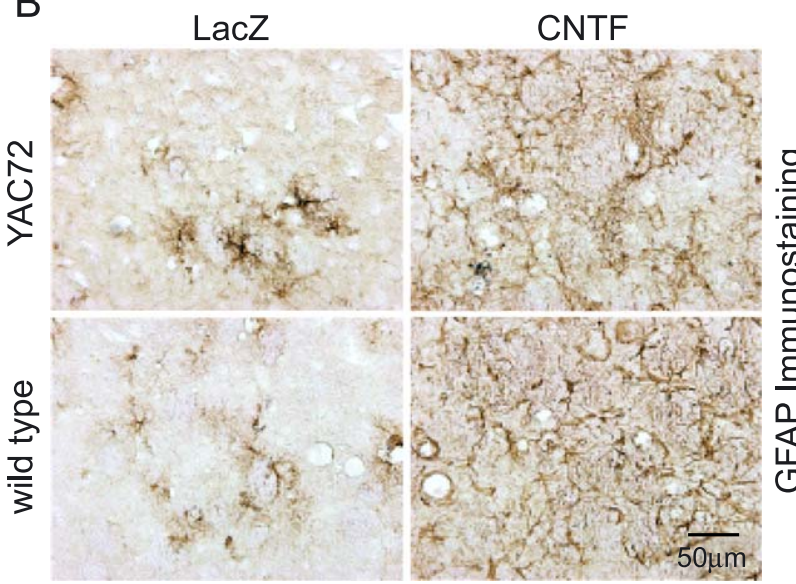

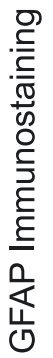

Fig. 7. Analysis of NeuN-stained striatal sections. (A) NeuN-stained striatal sections from WT-LacZ, WT-CNTF, YAC72-LacZ and YAC72-CNTF mice. (B) Evaluation of the astrocytic response in WT and YAC72 mice. Photomicrographs showing GFAP-stained striatal sections in WT-LacZ, WT-CNTF, YAC72-LacZ and YAC72-CNTF injected animals. The administration of CNTF for 9 months leads to a significant increase in GFAP immunoreactivity. In YAC72-lacZ mice, the staining did not differ from WT-LacZ animals. 
were not seen in wild-type LacZ mice (Fig. 4A). These differences in the observed pattern of LacZ expression may reflect the ongoing neurodegenerative process occurring in the YAC72 mice.

Dark cells

Cresyl violet-stained sections were used to reveal the presence of striatal dark cells and assess the effect of CNTF on the incidence of these cells. Dark hyperchromatic neurons were visible in YAC72-LacZ mice (Fig. 5A), whereas no sign of these cells was found in WT-LacZ and WT-CNTF animals. The intra-striatal administration of CNTF significantly reduced the number of dark cells: in YAC72-CNTF mice (60 \pm 16$)$ compared to YAC72-LacZ mice (129 \pm 12 ; $P<0.001$ ) (Figs. 5A and 5B). This effect was not limited to the injection site but was observed throughout the striatum (data not shown).

\section{DARPP-32 and NeuN immunoreactivity}

To further assess the effect of CNTF, stereological counts of DARPP-32-stained sections were performed. This marker of the striatal GABAergic spiny neurons (Ouimet et al., 1998 ) is decreased in several mouse models of HD (Bibb et al., 2000; Luthi-Carter et al., 2000; van Dellen et al., 2000). Interestingly, the long-term expression of CNTF in WT mice led to a decrease in DARPP-32 labeling as shown in Fig. 6A. The neuritic staining and the number of DARPP32 -positive neurons were reduced $\left(1.10 \times 10^{6} \pm 0.15\right)$ compared with WT-LacZ animals $\left(1.44 \times 10^{6} \pm 0.15 ; P=0.13\right)$ (Fig. 6B). Unfortunately, this result precludes drawing any conclusions from the YAC72 mice, on any potential protective effect of CNTF on medium spiny neurons (YAC72LacZ: $1.20 \times 10^{6} \pm 0.07$; YAC72-CNTF: $1.15 \times 10^{6} \pm$ 0.11 ). To further investigate the pathology of 13 -monthold YAC72 mice and the effect of CNTF administration, striatal sections were stained with the neuronal marker NeuN. No significant change in the staining and number of NeuN-positive cells was observed between WT-LacZ $\left(1.52 \times 10^{6} \pm 0.06\right)$ and YAC72-LacZ mice $\left(1.42 \times 10^{6} \pm\right.$ $0.10 ; P=0.2)$ whereas a reduction in the number of NeuNpositive neurons was observed in the CNTF-treated mice (WT-CNTF: $1.35 \times 10^{6} \pm 0.12 ;$ YAC72-CNTF: $1.04 \times 10^{6} \pm 0.07 ; P=0.01$ ) (Fig. 7A). Finally, immunohistochemical analysis of NADPH-d neurons, which are spared in HD patients, failed to reveal any alterations in the brain of WT and YAC72 mice treated or not with CNTF (data not shown).

\section{GFAP staining}

Previous in vitro and in vivo studies have shown that CNTF induces astrocyte differentiation (Kahn et al., 1995; Mayer et al., 1994; Winter et al., 1995). We have therefore performed a GFAP immunostaining to reveal the presence of activated astrocytes (Fig. 7B). Both WT-CNTF- and YAC72CNTF-injected animals showed a substantial GFAP immunoreactivity (Fig. 7), whereas only few GFAP-positive astrocytes were visible in WT-LacZ- and YAC72-LacZ-injected mice (Fig. 7).

\section{Discussion}

In the present study, we assessed the effect of local and long-term lentiviral-mediated CNTF expression in the striatum of wild-type and HD transgenic mice. Lentiviral vectors led to robust transgene expression up to 9 months postinjection in the striatum of mice (Déglon and Aebischer, 2002) and lentiviral-mediated CNTF delivery was shown to protect striatal neurons in a drug-induced rat model of HD (de Almeida et al., 2001). Lentiviruses expressing the LacZ reporter gene or human CNTF gene were therefore injected bilaterally in 4-month-old wild-type and YAC72 mice. Nine months post-injection, approximately 35,000 LacZ-infected cells were counted in wild-type mice, whereas a reduction in the number of $\beta$-galactosidase-positive cells was observed in five out of the six HD transgenic mice. The loss of LacZ expression may result from the ongoing pathological process occurring in YAC72 mice and suggests that this reporter gene could be used as a surrogate marker to follow the appearance of HD pathology in animal models lacking severe neurodegeneration. Whether this loss of LacZ staining is due to an aberrant transcriptional regulation of the reporter gene, as reported in various experimental paradigms of HD, still needs to be investigated. The cell bodies of some spared LacZ-positive neurons appear larger with an intense staining. This phenotype is reminiscent of the results published by Bence et al. (2001). They showed that cells coexpressing a mutated huntingtin fragment and a destabilized green fluorescent protein (GFP) have a 4-fold increase in GFP fluorescence compared to controls and that this phenomenon was due to an impairment of the ubiquitinproteasome pathway. Interestingly, no significant differences in CNTF expression were observed over time or between wild-type and YAC72 mice. This suggests that CNTF expression, contrary to LacZ, is not affected by mutated huntingtin or that CNTF is altering the ongoing pathology.

During the time-course examined in our experiments, the phenotype of YAC72 transgenic mice appears to correspond to early stages of the disease, with hyperactivity and neuronal dysfunction associated with the appearance of dark cells. While nuclear huntingtin staining increases around 12 months of age, very few huntingtin inclusions are identified. This experimental paradigm was used to assess the impact of a local and continuous expression of approximately $0.5 \mathrm{ng}$ human CNTF in the striatum. Wild-type FVB/N littermates were used as control. The development of hyperactivity on open-field testing was the first parameter examined to assess the disease 
progression and the impact of CNTF expression. Large inter- and intra-individual variability of spontaneous explorative behavior was observed, but significant differences were recorded between wild-type and transgenic mice at 5 and 8 months. This heterogeneity and the early stage of the pathology in YAC72 mice characterized by subtle changes, limits the number of validated outcome measures which can reliably be used to monitor the effects of potential therapeutic candidates. Nuclear inclusions are, for example, very rare in these animals and cannot be used as parameter. Recently, a new YAC128 transgenic mouse model of HD has been developed which has increased levels of transgene expression and an accelerated neurodegenerative phenotype that is more adequate for therapeutic trials (Slow et al., 2003).

Scattered atrophic neurons with condensed chromatin and a "dark" cytoplasm are present in affected areas of HD brains (Vonsattel and Difiglia, 1998). In 17-week-old R6/2 transgenic mice, degenerating neurons surrounded by neurons with normal appearance were detected in cerebellum and large number of brain regions. These dying neurons have a higher affinity for toluidine blue and exhibit nuclear inclusions and ruffling of the plasma membrane (Turmaine et al., 2000). Dark neurons were also observed in 5- to 7month-old R6/1 mice (Iannicola et al., 2000) and in 8- to 12month-old YAC72 mice (Hodgson et al., 1999). In our study, hyperchromatic and shrunken neurons were visible in YAC72-LacZ mice, and CNTF expression significantly decreases the number of dark neurons. Whether these dark cells represent a degenerating subpopulation of neurons is, however, unclear.

Mutant huntingtin expression is associated with regional and temporal alterations in gene expression (Neri, 2001; Nucifora et al., 2001; Shimohata et al., 2000; Sugars and Rubinsztein, 2003). Changes in the expression of transcription factors, neuronal markers, genes implicated in cellular metabolism or neurotransmitter receptors should, not only, provide important information related to polyQ-mediated neurodegeneration but also quantitative tools for the evaluation of therapeutic strategies. Histological studies on R6/2 animals has, for example, revealed a reduction in DARPP-32 and other dopamine-regulated proteins expressed in medium spiny neurons at 4-8 weeks (Bibb et al., 2000; van Dellen et al., 2000). DARPP-32 is a pivotal regulator of dopamine receptor signaling in the striatum and is therefore considered as a good marker of the pathology occurring in presymptomatic mice or early stage of the disease. Interestingly, CNTF expression induced a drastic down-regulation of DARPP-32 in wild-type mice 9 months post-lentiviral injection. This effect has not been observed when the same CNTF-expressing lentiviral vector was injected for 5-12 weeks in QA-lesioned rats (de Almeida et al., 2001; unpublished data) or when CNTF was delivered in 3-NP-lesioned primates by encapsulated genetically engineered BHK cells (Mittoux et al., 2000). How the long-term striatal expression of CNTF leads to a decrease in
DARPP-32 immunoreactivity, and how this change might affect striatal function still needs to be established. The continuous delivery of nanograms of CNTF was previously shown to drastically decrease the extent of striatal damage in drug-induced models of HD (de Almeida et al., 2001; Emerich et al., 1996, 1997a,b; Mittoux et al., 2000). Differences in the pathological processes between druginduced and genetic models of HD may lead to a differential effect of CNTF. The mode of action of this cytokine is still poorly understood and various intracellular pathways might be activated in various animal models of HD. The binding of the CNTF to the gp130/LIFR $\beta / C N T F R \alpha$ receptor complex has been shown to activate the Jack/STAT and PI3K/Akt signaling pathways (Alonzi et al., 2001). CNTF, in particular, induces the phosphorylation and nuclear translocation of Stat3, a protein inducing the transcription of Bcl-2 and Bcl-xL genes (Catlett-Falcone et al., 1999; Fukuda et al., 1998; Karni et al., 1999) and regulating the activity of several transcription factors such as Forkhead 1, CREB and NF-kB (Brunet et al., 1999; Du and Montminy, 1998; Kane et al., 1999; Ozes et al., 1999). Long-term expression of CNTF may affect striatal functions either directly or indirectly. It is well established that CNTF induces a phenotypic alteration of astrocytes in vivo (Gomes et al., 1999; Kahn et al., 1997a,b; Levison et al., 1998; Lisovoski et al., 1997; Winter et al., 1995). Consistent with this, we observed an up-regulation of the astrocytic marker GFAP in the striatum of Lenti-CNTF injected mice. This astrocytic response covers the entire striatum and is probably due to diffusion of CNTF throughout this structure. Recently, Albrecht et al. (2002) showed that CNTF treatment leads to an activation of spinal cord astrocytes, to the production of various growth factors and to an increased survival of CNS neurons compared to untreated astrocytes. They propose that cytokine-activated astrocytes have an enhanced buffering capacity leading to decreased levels of harmful energy metabolites, which may indirectly protect neurons. This same indirect CNTF-mediated mechanism could be activated in the striatum and therefore protect neurons undergoing degeneration. Chronic impairment of mitochondrial energy metabolism are indeed thought to be involved in neurodegenerative diseases, including HD.

Studies are needed to further assess CNTF effect on striatal functions and its impact on HD pathology corresponding not only to an early stage of the disease but also to grade 2-4 pathologies.

\section{Acknowledgments}

The authors thank Fabienne Pidoux, Maria Rey, Christel Sadeghi and Laurence Winkel for expert technical assistance and Philippe Hantraye for his helpful contribution to the stereological analysis. This work was supported in part by the Swiss National Science Foundation (N.D.), the Huntington 
Society of Canada (M.R.H. and B.R.L.), Huntington's Disease Society of America (M.R.H.), the Hereditary Disease Foundation (M.R.H.), and the Canadian Institutes of Health Research (M.R.H. and B.R.L.). Dr. Michael Hayden is a holder of a Canada Research Chair in Human Genetics.

\section{References}

Abicht, A., Lochmuller, H., 1999. Technology evaluation: CRIB (CNTF delivery) CytoTherapeutics Inc. Curr. Opin. Mol. Ther. 1, 645-650.

Aebischer, P., Schluep, M., Déglon, N., Joseph, J.M., Hirt, L., Heyd, B., Goddard, M., Hammang, J.P., Zurn, A.D., Kato, A.C., Regli, F., Baetge, E.E., 1996. Intrathecal delivery of CNTF using encapsulated genetically modified xenogeneic cells in amyotrophic lateral sclerosis patients. Nat. Med. 2, 696-699.

Albrecht, P.J., Dahl, J.P., Stoltzfus, O.K., Levenson, R., Levison, S.W., 2002. Ciliary neurotrophic factor activates spinal cord astrocytes, stimulating their production and release of fibroblast growth factor-2, to increase motor neuron survival. Exp. Neurol. 173, 46-62.

Alonzi, T., Middleton, G., Wyatt, S., Buchman, V., Betz, U.A., Muller, W., Musiani, P., Poli, V., Davies, A.M., 2001. Role of STAT3 and PI 3kinase/Akt in mediating the survival actions of cytokines on sensory neurons. Mol. Cell. Neurosci. 18, 270-282.

Anderson, K.D., Panayotatos, N., Corcoran, T.L., Lindsay, R.M., Wiegand, S.J., 1996. Ciliary neurotrophic factor protects striatal output neurons in an animal model of Huntington disease. Proc. Natl. Acad. Sci. U. S. A. 93, 7346-7351.

Andrew, S.E., Goldberg, Y.P., Kremer, B., Telenius, H., Theilmann, J., Adam, S., Starr, E., Squitieri, F., Lin, B., Kalchman, M.A., et al., 1993. The relationship between trinucleotide (CAG) repeat length and clinical features of Huntington's disease. Nat. Genet. 4, 329-330.

Araujo, D.M., Hilt, D.C., 1998. Glial cell line-derived neurotrophic factor attenuates the locomotor hypofunction and striatonigral neurochemical deficits induced by chronic systemic administration of the mitochondrial toxin 3-nitropropionic acid. Neuroscience 82, 117-127.

Bemelmans, A.P., Horellou, P., Pradier, L., Brunet, I., Colin, P., Mallet, J., 1999. Brain-derived neurotrophic factor-mediated protection of striatal neurons in an excitotoxic rat model of Huntington's disease, as demonstrated by adenoviral gene transfer. Hum. Gene Ther. 10, 2987-2997.

Bence, N.F., Sampat, R.M., Kopito, R.R., 2001. Impairment of the ubiquitin proteasome system by protein aggregation. Science 292, 1552-1555.

Bibb, J.A., Yan, Z., Svenningsson, P., Snyder, G.L., Pieribone, V.A., Horiuchi, A., Nairn, A.C., Messer, A., Greengard, P., 2000. Severe deficiencies in dopamine signaling in presymptomatic Huntington's disease mice. Proc. Natl. Acad. Sci. U. S. A. 97, 6809-6814.

Brunet, A., Bonni, A., Zigmond, M.J., Lin, M.Z., Juo, P., Hu, L.S., Anderson, M.J., Arden, K.C., Blenis, J., Greenberg, M.E., 1999. Akt promotes cell survival by phosphorylating and inhibiting a Forkhead transcription factor. Cell 96, 857-868.

Catlett-Falcone, R., Landowski, T.H., Oshiro, M.M., Turkson, J., Levitzki, A., Savino, R., Ciliberto, G., Moscinski, L., Fernandez-Luna, J.L., Nunez, G., Dalton, W.S., Jove, R., 1999. Constitutive activation of Stat3 signaling confers resistance to apoptosis in human U266 myeloma cells. Immunity 10, 105-115.

de Almeida, L.P., Zala, D., Aebischer, P., Déglon, N., 2001. Neuroprotective effect of a CNTF-expressing lentiviral vector in the quinolinic acid rat model of Huntington's disease. Neurobiol. Dis. 8, 433-446.

Déglon, N., Aebischer, P., 2002. Lentiviruses as vectors for CNS diseases. Curr. Top. Microbiol. Immunol., 191-209.

Déglon, N., Tseng, J.L., Bensadoun, J.C., Zurn, A.D., Arsenijevic, Y., De Almeida, L.P., Zufferey, R., Trono, D., Aebischer, P., 2000. Self-inactivating lentiviral vectors with enhanced transgene expression as potential gene transfer system in Parkinson's disease. Hum. Gene Ther. $11,179-190$.
Du, K., Montminy, M., 1998. CREB is a regulatory target for the protein kinase Akt/PKB. J. Biol. Chem. 273, 32377-32379.

Dull, T., Zufferey, R., Kelly, M., Mandel, R.J., Nguyen, M., Trono, D., Naldini, L., 1998. A third-generation lentivirus vector with a conditional packaging system. J. Virol. 72, 8463-8471.

Ellison, D.W., Kowall, N.W., Martin, J.B., 1987. Subset of neurons characterized by the presence of NADPH-diaphorase in human substantia innominata. J. Comp. Neurol. 260, 233-245.

Emerich, D.F., Lindner, M.D., Winn, S.R., Chen, E.Y., Frydel, B.R., Kordower, J.H., 1996. Implants of encapsulated human CNTF-producing fibroblasts prevent behavioral deficits and striatal degeneration in a rodent model of Huntington's disease. J. Neurosci. 16, 5168-5181.

Emerich, D.F., Cain, C.K., Greco, C., Saydoff, J.A., Hu, Z.Y., Liu, H., Lindner, M.D., 1997a. Cellular delivery of human CNTF prevents motor and cognitive dysfunction in a rodent model of Huntington's disease. Cell Transplant 6, 249-266.

Emerich, D.F., Winn, S.R., Hantraye, P.M., Peschanski, M., Chen, E.Y., Chu, Y., McDermott, P., Baetge, E.E., Kordower, J.H., 1997b. Protective effect of encapsulated cells producing neurotrophic factor cntf in a monkey model of Huntington's disease. Nature 386, 395-399.

Frim, D.M., Short, M.P., Rosenberg, W.S., Simpson, J., Breakefield, X.O., Isacson, O., 1993. Local protective effects of nerve growth factor-secreting fibroblasts against excitotoxic lesions in the rat striatum. J. Neurosurg. 78, 267-273.

Fukuda, A., Deshpande, S.B., Shimano, Y., Nishino, H., 1998. Astrocytes are more vulnerable than neurons to cellular $\mathrm{Ca} 2+$ overload induced by a mitochondrial toxin, 3-nitropropionic acid. Neuroscience 87 , 497-507.

Gomes, F.C., Paulin, D., Moura Neto, V., 1999. Glial fibrillary acidic protein (GFAP): modulation by growth factors and its implication in astrocyte differentiation. Braz. J. Med. Biol. Res. 32, 619-631.

Hodgson, J.G., Agopyan, N., Gutekunst, C.A., Leavitt, B.R., LePiane, F., Singaraja, R., Smith, D.J., Bissada, N., McCutcheon, K., Nasir, J., Jamot, L., Li, X.J., Stevens, M.E., Rosemond, E., Roder, J.C., Phillips, A.G., Rubin, E.M., Hersch, S.M., Hayden, M.R., 1999. A YAC mouse model for Huntington's disease with full-length mutant huntingtin, cytoplasmic toxicity, and selective striatal neurodegeneration. Neuron 23, $181-192$.

Hottinger, A.F., Azzouz, M., Déglon, N., Aebischer, P., Zurn, A.D., 2000. Complete and long-term rescue of lesioned adult motoneurons by lentiviral-mediated expression of glial cell line-derived neurotrophic factor in the facial nucleus. J. Neurosci. 20, 5587-5593.

Iannicola, C., Moreno, S., Oliverio, S., Nardacci, R., Ciofi-Luzzatto, A., Piacentini, M., 2000. Early alterations in gene expression and cell morphology in a mouse model of Huntington's disease. J. Neurochem. 75, $830-839$.

Ip, N.Y., Yancopoulos, G.D., 1996. The neurotrophins and CNTF: two families of collaborative neurotrophic factors. Annu. Rev. Neurosci. 19, 491-515.

Kahn, M.A., Ellison, J.A., Speight, G.J., de Vellis, J., 1995. CNTF regulation of astrogliosis and the activation of microglia in the developing rat central nervous system. Brain Res. 685, 55-67.

Kahn, M.A., Ellison, J.A., Chang, R.P., Speight, G.J., de Vellis, J., 1997a. CNTF induces GFAP in a S-100 alpha brain cell population: the pattern of CNTF-alpha R suggests an indirect mode of action. Brain Res. Dev. Brain Res. 98, 221-233.

Kahn, M.A., Huang, C.J., Caruso, A., Barresi, V., Nazarian, R., Condorelli, D.F., deVellis, J., 1997b. Ciliary neurotrophic factor activates JAK/Stat signal transduction cascade and induces transcriptional expression of glial fibrillary acidic protein in glial cells. J. Neurochem. 68, 1413-1423.

Kane, L.P., Shapiro, V.S., Stokoe, D., Weiss, A., 1999. Induction of NFkappaB by the Akt/PKB kinase. Curr. Biol. 9, 601-604.

Karni, R., Jove, R., Levitzki, A., 1999. Inhibition of pp60 c-Src reduces Bcl-XL expression and reverses the transformed phenotype of cells overexpressing EGF and HER-2 receptors. Oncogene 18, $4654-4662$. 
Levison, S.W., Hudgins, S.N., Crawford, J.L., 1998. Ciliary neurotrophic factor stimulates nuclear hypertrophy and increases the GFAP content of cultured astrocytes. Brain Res. 803, 189-193.

Lisovoski, F., Akli, S., Peltekian, E., Vigne, E., Haase, G., Perricaudet, M., Dreyfus, P.A., Kahn, A., Peschanski, M., 1997. Phenotypic alteration of astrocytes induced by ciliary neurotrophic factor in the intact adult brain, as revealed by adenovirus-mediated gene transfer. J. Neurosci. $17,7228-7236$

Luthi-Carter, R., Strand, A., Peters, N.L., Solano, S.M., Hollingsworth, Z.R., Menon, A.S., Frey, A.S., Spektor, B.S., Penney, E.B., Schilling, G., Ross, C.A., Borchelt, D.R., Tapscott, S.J., Young, A.B., Cha, J.H., Olson, J.M., 2000. Decreased expression of striatal signaling genes in a mouse model of Huntington's disease. Hum. Mol. Genet. 9, 1259-1271.

Mayer, M., Bhakoo, K., Noble, M., 1994. Ciliary neurotrophic factor and leukemia inhibitory factor promote the generation, maturation and survival of oligodendrocytes in vitro. Development 120, 143-153.

Mittoux, V., Joseph, J.M., Conde, F., Palfi, S., Dautry, C., Poyot, T., Bloch, J., Déglon, N., Ouary, S., Nimchinsky, E.A., Brouillet, E., Hof, P.R., Peschanski, M., Aebischer, P., Hantraye, P., 2000. Restoration of cognitive and motor functions by ciliary neurotrophic factor in a primate model of Huntington's disease. Hum. Gene Ther. 11, 1177-1187.

Naldini, L., Blomer, U., Gallay, P., Ory, D., Mulligan, R., Gage, F.H., Verma, I.M., Trono, D., 1996. In vivo gene delivery and stable transduction of nondividing cells by a lentiviral vector. Science $272,263-267$.

Neri, C., 2001. New light on polyglutamine neurodegenerative disorders: interference with transcription. Trends Mol. Med. 7, 283-284.

Nucifora Jr., F.C., Sasaki, M., Peters, M.F., Huang, H., Cooper, J.K., Yamada, M., Takahashi, H., Tsuji, S., Troncoso, J., Dawson, V.L., Dawson, T.M., Ross, C.A., 2001. Interference by huntingtin and atrophin-1 with cbp-mediated transcription leading to cellular toxicity. Science 291, 2423-2428.

Ouimet, C.C., Langley-Gullion, K.C., Greengard, P., 1998. Quantitative immunocytochemistry of DARPP-32-expressing neurons in the rat caudatoputamen. Brain Res. 808, 8-12.

Ozes, O.N., Mayo, L.D., Gustin, J.A., Pfeffer, S.R., Pfeffer, L.M., Donner, D.B., 1999. NF-kappaB activation by tumour necrosis factor requires the Akt serine-threonine kinase. Nature 401, 82-85.

Penn, R.D., Kroin, J.S., York, M.M., Cedarbaum, J.M., 1997. Intrathecal ciliary neurotrophic factor delivery for treatment of amyotrophic lateral sclerosis (phase I trial). Neurosurgery 40.

Perez-Navarro, E., Alberch, J., Neveu, I., Arenas, E., 1999. Brain-derived neurotrophic factor, neurotrophin-3 and neurotrophin- $4 / 5$ differentially regulate the phenotype and prevent degenerative changes in striatal projection neurons after excitotoxicity in vivo. Neuroscience 91, $1257-1264$.

Perez-Navarro, E., Akerud, P., Marco, S., Canals, J.M., Tolosa, E., Arenas, E., Alberch, J., 2000. Neurturin protects striatal projection neurons but not interneurons in a rat model of Huntington's disease. Neuroscience 98, 89-96

Saudou, F., Finkbeiner, S., Devys, D., Greenberg, M.E., 1998. Huntingtin acts in the nucleus to induce apoptosis but death does not correlate with the formation of intranuclear inclusions. Cell 95, 55-66.

Shimohata, T., Nakajima, T., Yamada, M., Uchida, C., Onodera, O., Naruse, S., Kimura, T., Koide, R., Nozaki, K., Sano, Y., Ishiguro, H., Sakoe, K., Ooshima, T., Sato, A., Ikeuchi, T., Oyake, M., Sato, T., Aoyagi, Y., Hozumi, I., Nagatsu, T., Takiyama, Y., Nishizawa, M., Goto, J., Kanazawa, I., Davidson, I., Tanese, N., 2000. Expanded polyglutamine stretches interact with TAFII130, interfering with CREB-dependent transcription. Nat. Genet. 26, 29-36.

Slow, E.J., van Raamsdonk, J., Rogers, D., Coleman, S.H., Graham, R.K., Deng, Y., Oh, R., Bissada, N., Hossain, S.M., Yang, Y.-Z., Li, X.-J., Simpson, E.M., Gutekunst, C.-A., Leavitt, B.R., Hayden, M.R., 2003. Selective striatal neuronal loss in a YAC128 mouse model of Huntington disease. Hum. Mol. Genet. 12, 1555-1567.

Sugars, K.L., Rubinsztein, D.C., 2003. Transcriptional abnormalities in Huntington disease. Trends Genet. 19, 233-238.

The Huntington's Disease Collaborative Research Group, 1993. A novel gene containing a trinucleotide repeat that is expanded and unstable on Huntington's disease chromosomes. The Huntington's Disease Collaborative Research Group. Cell 72, 971-983.

Turmaine, M., Raza, A., Mahal, A., Mangiarini, L., Bates, G.P., Davies, S.W., 2000. Nonapoptotic neurodegeneration in a transgenic mouse model of Huntington's disease. Proc. Natl. Acad. Sci. U. S. A. 97, 8093-8097.

van Dellen, A., Welch, J., Dixon, R.M., Cordery, P., York, D., Styles, P., Blakemore, C., Hannan, A.J., 2000. N-acetylaspartate and DARPP-32 levels decrease in the corpus striatum of Huntington's disease mice. NeuroReport 11, 3751-3757.

Volpe, B.T., Wildmann, J., Altar, C.A., 1998. Brain-derived neurotrophic factor prevents the loss of nigral neurons induced by excitotoxic striatal-pallidal lesions. Neuroscience 83, 741-748.

Vonsattel, J.P., Difiglia, M., 1998. Huntington disease. J. Neuropathol. Exp. Neurol. 57, 369-384.

Winter, C.G., Saotome, Y., Levison, S.W., Hirsh, D., 1995. A role for ciliary neurotrophic factor as an inducer of reactive gliosis, the glial response to central nervous system injury. Proc. Natl. Acad. Sci. U. S. A. 92, $5865-5869$. 